\title{
Constriction (banding) of Blalock-Taussig anastom
for intractable congestive cardiac failure and pulmonary oedema
}

\author{
J. C.R. L I N C OLN, J. ST ARK, M. J. T Y NAN, A N D \\ E. A BER DEEN
}

From the Thoracic Unit, the Hospital for Sick Children, Great Ormond Street, London, W.C.I

Two young patients with complex congenital heart disease developed congestive cardiac failure and unilateral pulmonary oedema following palliative Blalock-Taussig pulmonary artery to systemic artery shunts. Following the failure of medical therapy these shunts were constricted by using braided silk ligature material, after which the heart failure and pulmonary oedema resolved.

A transient degree of congestive cardiac failure is not uncommon after a systemic artery to pulmonary artery shunt performed as a palliative procedure for complex congenital heart disease. Young patients who have such heart disease-for example, Fallot's anomaly (or tetralogy), pulmonary atresia, or transposition of the great arteries with pulmonary stenosis - frequently benefit from these shunts prior to final corrective surgery. Albers and Nadas (1967) have recently reported three patients with chronic unilateral pulmonary oedema and pleural effusion after systemic pulmonary artery shunts for cyanotic congenital heart disease. These three were controlled with medical therapy. The contralateral pulmonary artery was hypoplastic in two patients and in the third it was completely occluded.

We report two patients who had palliative systemic-pulmonary artery shunts performed for cyanotic heart disease and who subsequently developed chronic congestive cardiac failure and unilateral pulmonary oedema despite intensive medical therapy. Because these patients were not controlled by medical therapy the subclavian artery used for the systemic-pulmonary artery shunt was constricted (banded), with good effect.

\section{CASE REPORTS}

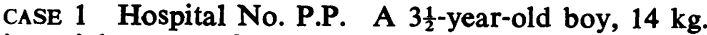
in weight, was referred to the Hospital for Sick Children, Great Ormond Street, London, with a diagnosis of transposition of the great arteries. Subsequent investigations confirmed this diagnosis and in addition demonstrated a ventricular septal defect and infundibular and valvar pulmonary stenosis. The child'so exercise tolerance was limited. He was cyanosed andక had clubbing of the fingers. The chest radiograph showed an enlarged heart with oligaemic lung fieldso (Fig. 1a).

On 25 May 1967 a Blalock-Hanlon atrial septo stomy (Blalock and Hanlon, 1950) and a righte Blalock-Taussig systemic-pulmonary artery shunt were performed (Blalock and Taussig, 1945), the latter giving an $8 \mathrm{~mm}$. shunt at the anastomosis. Within $36^{\circ}$. hours signs of congestive cardiac failure and unilateral pulmonary oedema were present (Fig. 1b). The childe was immediately digitalized and given chlorothiazide and a low salt diet, but this regime had little effect.o The heart failure continued to increase and one month 3 . after the operation he was in intractable congestiveo cardiac failure despite rigorous antifailure therapy, which then included frusemide (Fig. 1c). The jugular venous pressure was higher than the angle of the mandible when measured in the routine way, and there was pitting oedema of the legs up to the kneese. and a pad of sacral oedema. As the medical therapyn had failed it was assumed that the flow through the Blalock-Taussig shunt was too great and that an attempt should be made to reduce this flow by con N stricting the right subclavian artery proximal to the anastomosis. On 21 June 1967 the right subclavian artery was dissected out and a ligature of braided silk was passed around the vessel. Operative manometryes was not available. Using a sterile stethoscope with the bell placed over the hilum of the right lung, the subclavian artery was narrowed until the shunt murmur diminished in intensity but was not completely abolished. The thrill was also lessened. He continuedo with the same drugs as before operation and there was an almost immediate decrease of the heart failure. The jugular venous pressure fell to $3 \mathrm{~cm}$. above the 


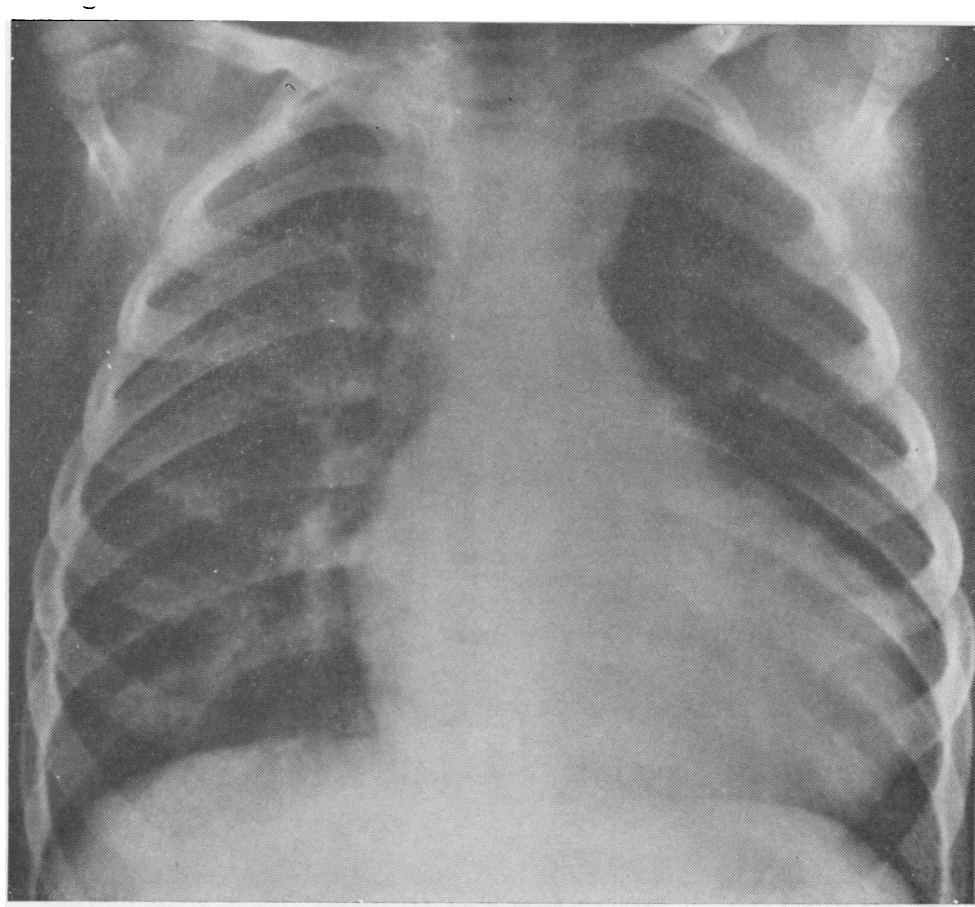

FIG. 1a. Case 1. Pre-operative postero-anterior chest radiograph showing an enlarged heart.

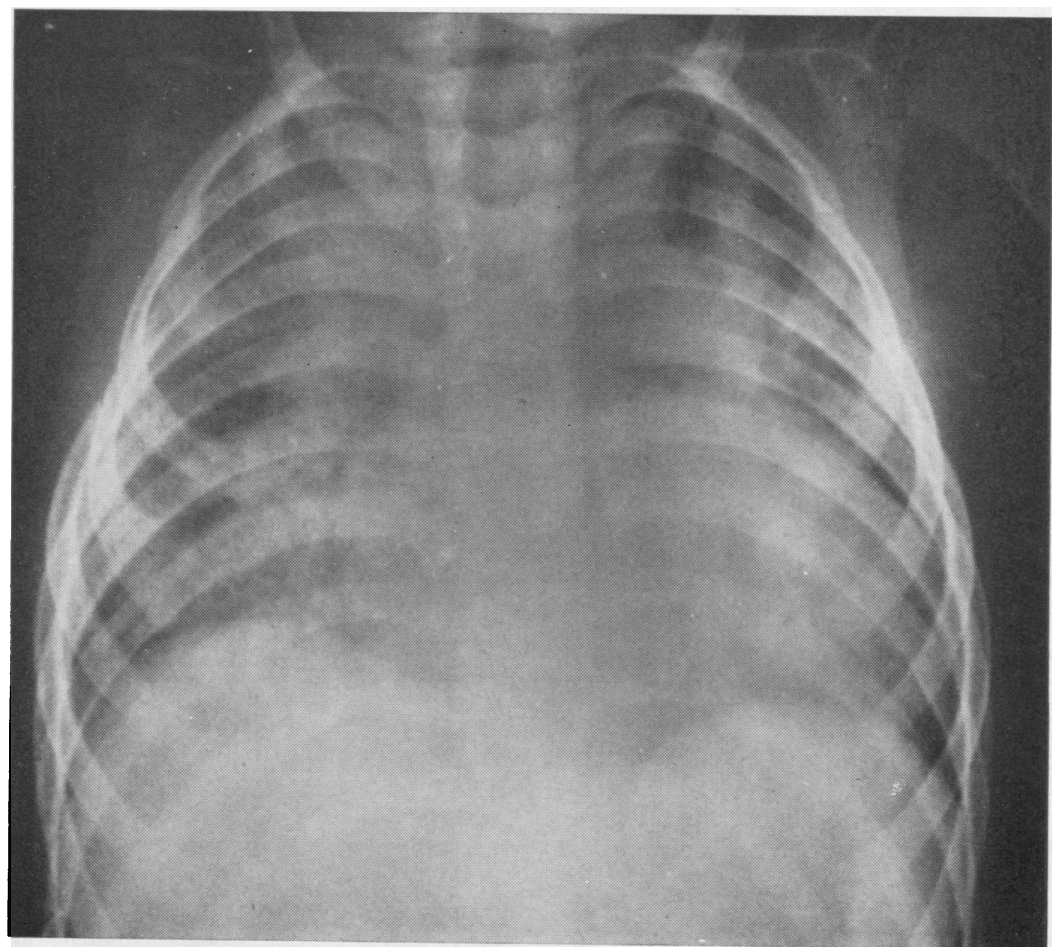

FIG. 1b. Case 1. Chest radiograph taken 36 hours after the Blalock-Hanlon and Blalock-Taussig operations. 


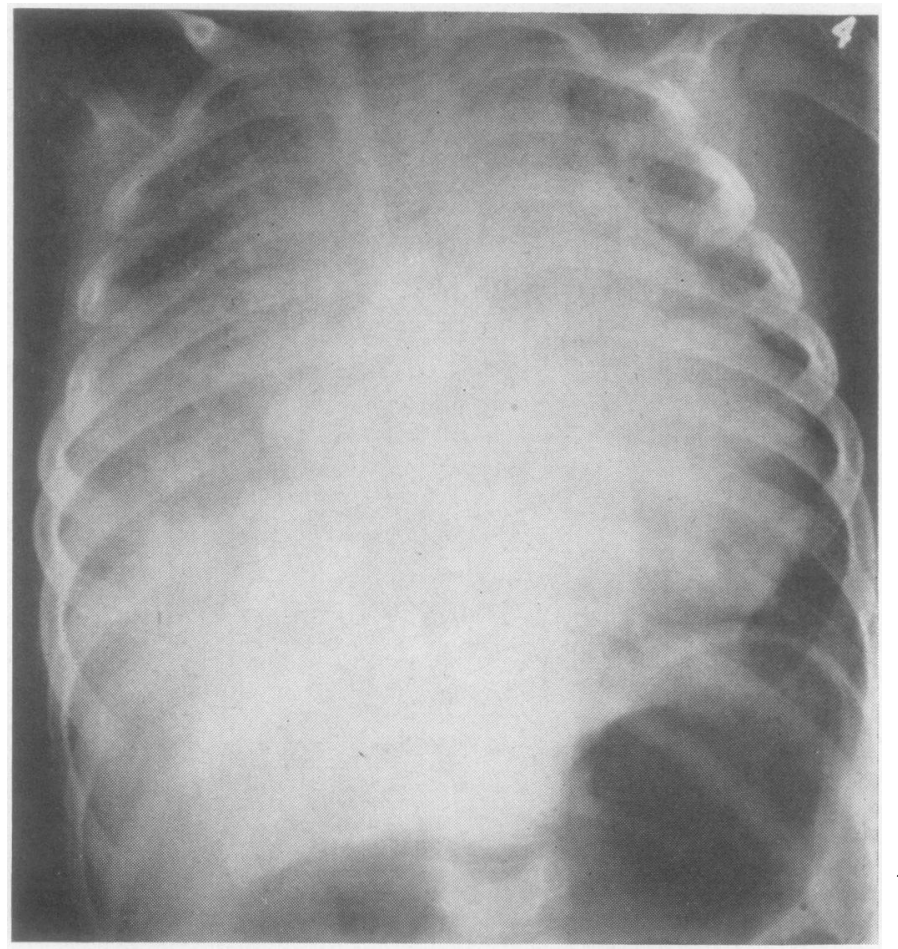

FIG. 1c. Case 1. Postero-anterior chest radiograph one month after the Blalock $\underset{\perp}{N}$ Hanlon and Blalock-Taussig operations.

FIG. 1d. Case 1. Chest radiograph 15 days after constriction of BlalockTaussig shunt.

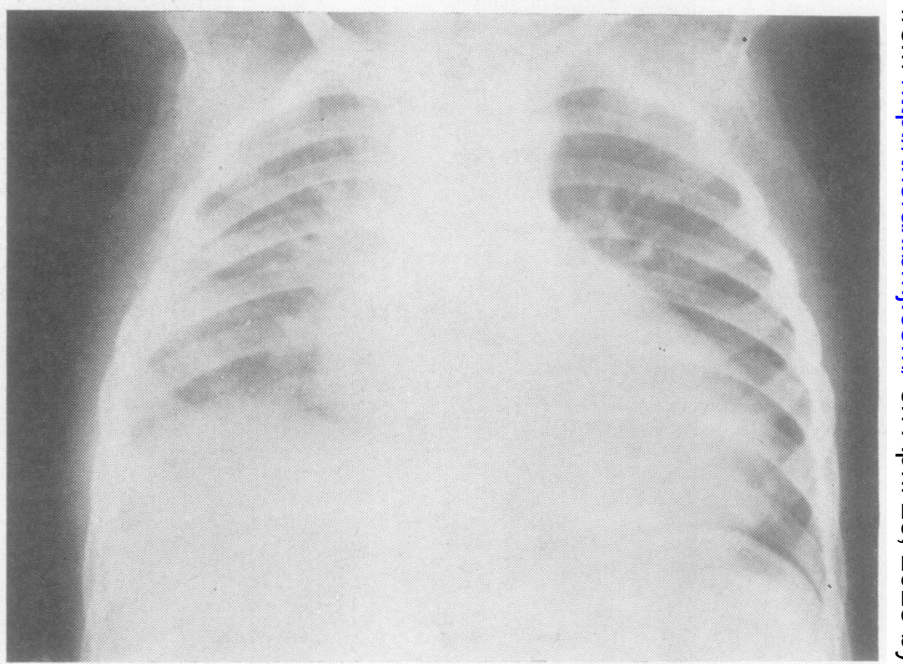

manubrio-sternal angle and the sacral and leg oedema resolved. A chest radiograph (Fig. 1d) showed clearing of the pulmonary oedema and his weight fell dramatically (Fig. 2). He was discharged on maintenance doses of digoxin and diuretics and has continued to improve greatly.

CASE 2 Hospital No. 332159. This 6-year-old, 15-kg. girl was admitted to hospital for reassessment of her congenital heart disease on 10 July 1967. She haf్ been cyanosed since birth and cardiac catheterization and angiography at 3 months of age demonstrated $a_{0}$ severe tetralogy of Fallot. The child was then los5 to follow-up and was not seen again at the hospita until five years later, when her cyanosis was much worse, she squatted frequently, and suffered fron® repeated chest infections. Further investigation cone firmed the above cardiac defect. In October 1966 


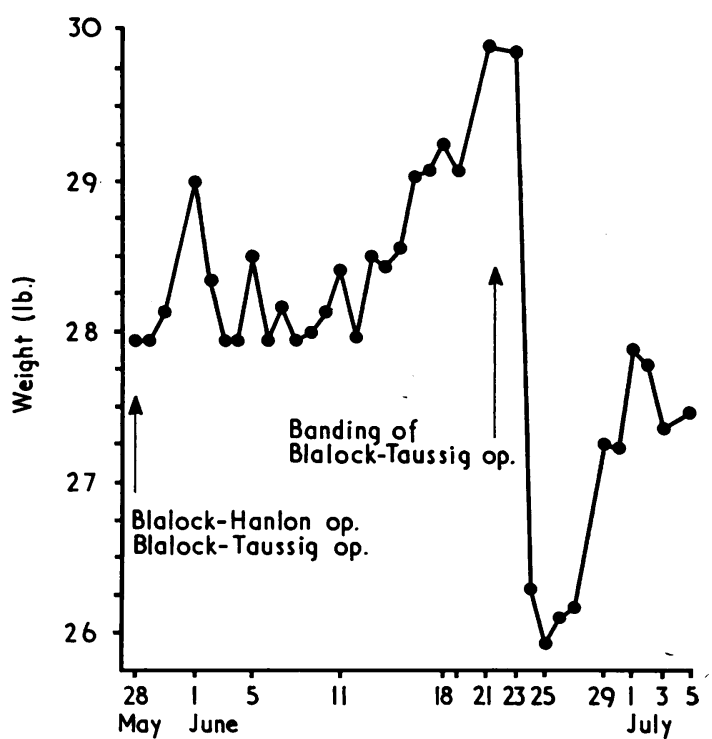

FIG. 2. Case 1. Weight chart showing progressive increase in weight following the initial operation and a dramatic decrease in weight following constriction of the BlalockTaussig shunt.

right Blalock-Taussig shunt was performed; the diameter of the anastomosis was $5 \mathrm{~mm}$. A chest radiograph taken at this time showed a moderately enlarged heart (Fig. 3a). For six months after the operation she was greatly improved, her cyanosis was less, her exercise tolerance improved, and she stopped squatting. However, seven months after this shunt had been performed her condition began to deteriorate, she became lethargic and irritable, and her exercise tolerance decreased.

Clinically there were signs of gross congestive cardiac failure with the liver enlarged to below the level of the umbilicus. Chest radiography showed cardiomegaly and pulmonary oedema (Fig. 3b). Because of the now unsatisfactory state of her cardiovascular system she was placed on intensive medical therapy-namely, digoxin, frusemide, and a low salt diet. Subsequent cardiac catheterization and angiography showed a functioning right Blalock-Taussig anastomosis and the main pulmonary artery pressure was $70 / 40 \mathrm{~mm}$. Hg. The other findings were once again compatible with a severe tetralogy of Fallot. After a month of medical treatment there was no change in the child's condition. Excessive flow through the shunt appeared to be responsible for the heart failure. The pressure in the main pulmonary artery was $70 / 40 \mathrm{~mm}$. $\mathrm{Hg}$, and it was decided that the shunt should be constricted as in case 1 .

In August 1967 the right subclavian artery was constricted using a similar technique to that described, but on this occasion operative manometry was available and the pressure in the right pulmonary artery distal to the band was reduced to $50 \mathrm{~mm}$. of mercury. Further tightening of the band tended to occlude the shunt completely. We were apprehensive that such a small reduction in pressure would have little or no effect, but following this procedure she made rapid progress, as judged by her clinical state, reduction of the congestive cardiac failure, and resolution of her pulmonary oedema (Fig. 3c). The digoxin and diuretics were reduced to maintenance doses and she was discharged.

\section{DISCUSSION}

It is not intended in this paper to discuss the complications of systemic-pulmonary artery shunts as these are well documented.

Although the ascending aorta to right pulmonary artery shunts (Waterston, 1962) and the left pulmonary artery to descending thoracic aorta shunts (Potts, Smith, and Gibson, 1946) have been incriminated more frequently than the BlalockTaussig shunt as causing congestive cardiac failure, provided the size of the anastomosis is not too large only transient degrees of congenital cardiac failure should occur. However, it is admitted that the diameter of the anastomosis may be more critical in the aforementioned shunts which could allow large left to right shunts, namely the Waterston and Potts shunt.

In the early post-operative period slight cardiac enlargement can be anticipated in any systemic artery to pulmonary artery shunt, but such enlargement should not persist if the shunt is not to have a deleterious effect on cardiac function.

Paul, Miller, and Potts (1961), in an analysis of their first one hundred cases of aortic-pulmonary anastomosis for tetralogy of Fallot, were able to follow up 92 of these patients. Nine late deaths were recorded, and in five of these the cause of death was given as congestive cardiac failure and they died at an interval of 2 to 13 years after surgery. No details are given of their medical treatment, but it is stated that the long-term morbidity and poor results were 'most likely related to the presence of too large an anastomosis, leading to either left ventricular overwork and congestive heart failure or to severe pulmonary hypertension and probably progressive pulmonary obstruction and a decreasing aortic-pulmonary shunt'.

In a five-year (White, McNamara, Bauersfeld, and Taussig, 1956) and then a 10- to 13-year follow-up (Taussig, Crawford, Pelargonio, and Zacharioudakis, 1962) on one group of patients treated with a Blalock-Taussig anastomosis a low incidence of congestive cardiac failure is reported, only five patients, or $2.2 \%$ in 224 patients, show- 


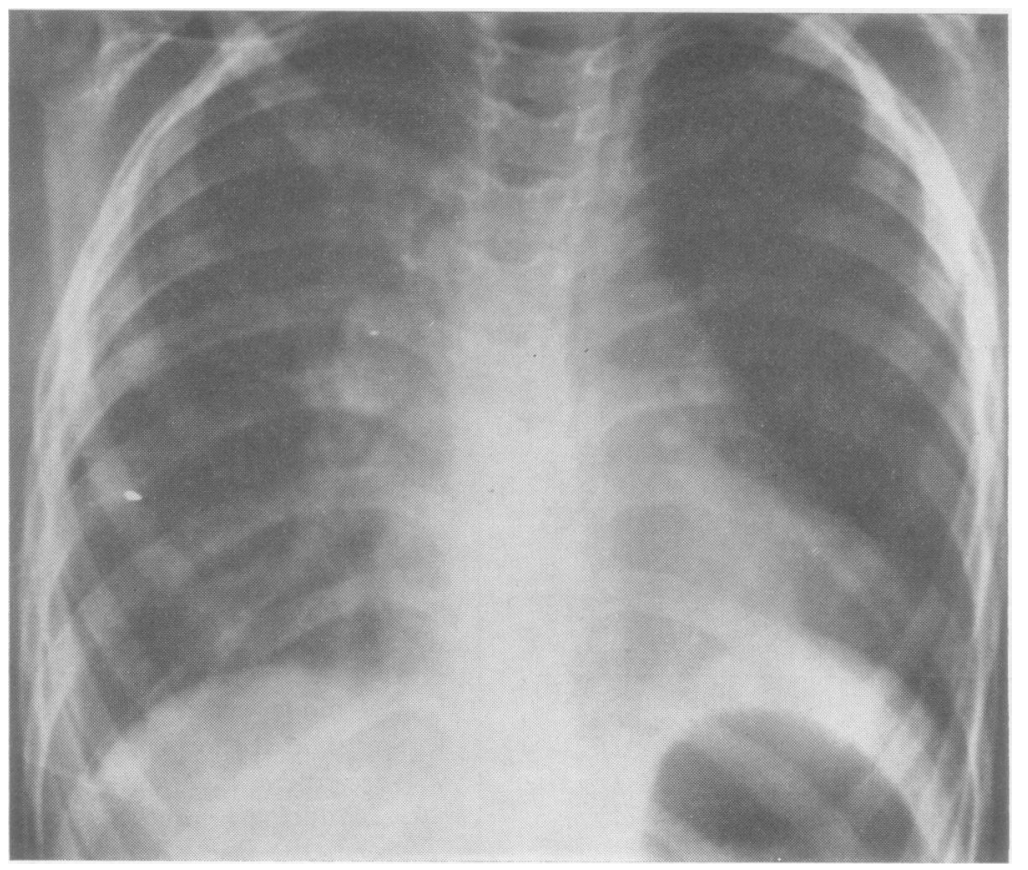

FIG. 3a. Case.2. Post-operative chest radiograph taken immediately after the Blalock-Taussig operation in October 1966.气

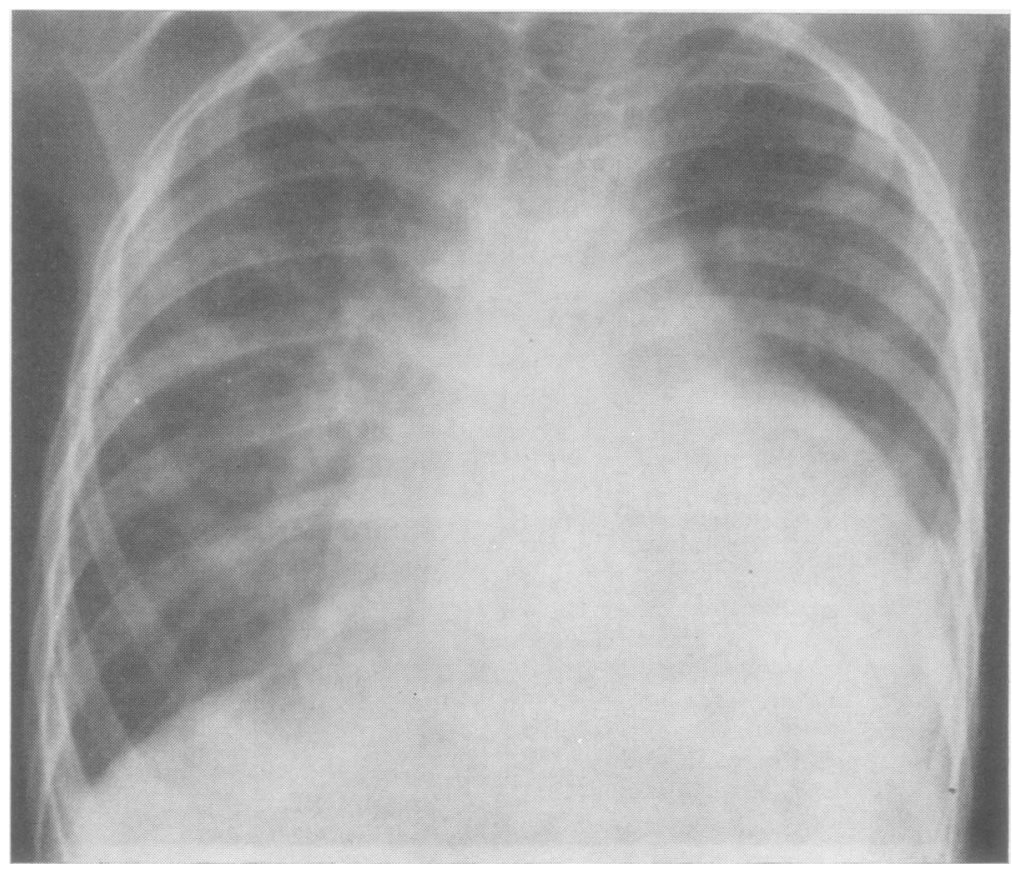




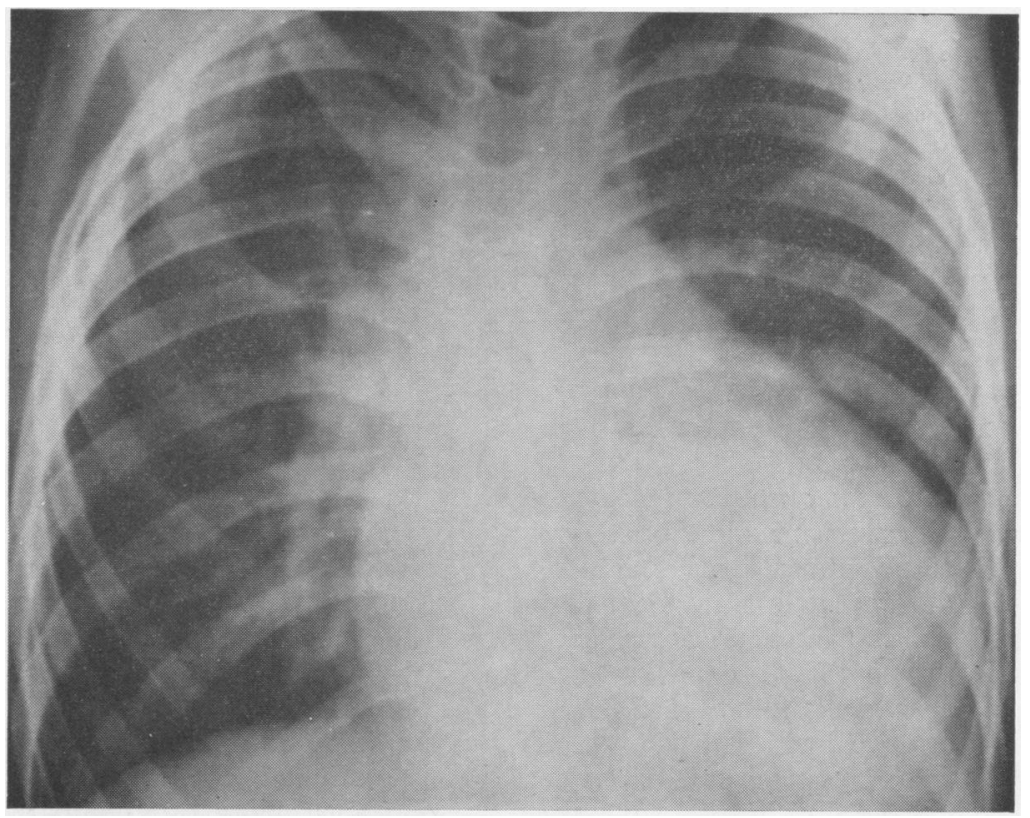

FIG. 3c. Case 2. Chest radiograph one month after constriction of the Blalock-Taussig anastomosis.

ing signs of congestive cardiac failure in the 10to 13-year follow-up, and only 2 of the 33 'late deaths' in the five-year follow-up were attributed to cardiac failure.

In these two reported cases congestive cardiac failure developed early in one patient and late in the other, but unilateral pulmonary oedema occurred in both. There was no evidence of contralateral pulmonary artery hypoplasia, as judged by cardiac catheterization and angiography, in contrast to the three cases reported by Albers and Nadas (1967).

Although late deaths due to congestive cardiac failure have been reported in patients in whom pulmonary systemic shunts have been carried out for complex congenital cardiac anomalies (Ross, Taussig, and Evans, 1958), it is likely that the incidence of such deaths must decrease as final corrective surgery is carried out at an earlier age, thus obviating prolonged heart failure.

Constriction (banding) of the subclavian artery component of the Blalock-Taussig shunt is a useful method of overcoming the intractable heart failure and pulmonary oedema which very occasionally follow such shunts.
We wish to thank Dr. R. E. Bonham-Carter for support in managing these patients. We are very grateful to the Photographic Department for photographic reproductions of the radiographs.

\section{REFERENCES}

Albers, W. H., and Nadas, A. S. (1967). Unilateral chronic pulmonary edema and pleural effusion after systemic-pulmonary artery shunts for cyanotic congenital heart disease. Amer. J. Cardiol., 19,861 .

Blalock, A., and Hanlon, C. R. (1950). The surgical treatment of complete transposition of the aorta and the pulmonary artery. Surg. Gynec. Obstet., 90, 1.

- and Taussig, H. B. (1945). The surgical treatment of malformations of the heart in which there is pulmonary stenosis or pulmonary atresia. J. Amer. med. Ass., 128, 189.

Paul, M. H., Miller, R. A., and Potts, W. J. (1961). Long-term results of aortic-pulmonary anastomosis for tetralogy of Fallot. An analysis of the first 100 cases eleven to thirteen years after operation. Circulation, 23, 525 .

Potts, W. J., Smith, S., and Gibson, S. (1946). Anastomosis of the aorta to a pulmonary artery. Certain types of congenital heart disease. J. Amer. med. Ass., 132, 627.

Ross, R. S., Taussig, H. B., and Evans, M. H. (1958). Late hemodynamic complications of anastomotic surgery for treatment of the tetralogy of Fallot. Circulation, 18, 553.

Taussig, H. B., Crawford, H., Pelargonio, S., and Zacharioudakis, S. (1962). Ten to thirteen year follow-up on patients after a BlalockTaussig operation. Ibid., 25, 630 .

Waterston, D. J. (1962). The treatment of Fallot's tetralogy in infants under the age of one year. Rozhl. Chir., 41, no. 3, 181. (In Czech.)

White, B. D., McNamara, D. G., Bauersfeld, S. R., and Taussig, H. B. (1956). Five-year postoperative results of first 500 patients with Blalock-Taussig anastomosis for pulmonary stenosis or atresia. Circulation, 14, 512 . 